\title{
Myringoplasty: comparison between different tissues grafts, a prospective study
}

\begin{abstract}
Myringoplasty is done to repair simple perforations of the pars tensa. Different tissue grafts such as temporalis fascia, lobule fat, tragal perichondrium, cartilage from tragus and helix, cartilage-perichondrium composite graft and vein grafts have been used historically with varying success rates. In this study, we have used temporalis fascia, ear lobule fat and tragal perichondrium as graft material for myringoplasty and divided the study population into three groups based on the graft used. The outcome of the surgery across the three groups have been compared in terms of successful graft uptake and hearing improvement to less than or equal to $25 \mathrm{~dB}$ using pure tone audiometry. The group where temporalis fascia was used showed greater graft uptake rate $(88.71 \%)$. Hearing improvement was however comparable in all the three groups ( $80.64 \%$ in the temporalis fascia group, $81.57 \%$ in the lobule fat group \& $81.25 \%$ in the perichondrium group).
\end{abstract}

Volume 10 Issue 3 - 2018

\author{
Swagata Khanna \\ Head of the Department of ENT, Gauhati Medical College, India
}

Correspondence: Swagata Khanna, Former Professor and Head of the Department of ENT, Director and Chief ENT Consultant, Swagat Super Speciality Surgical Institute, Maligaon, Guwahati, India, Tel 09864094I40,

Email drswagatakhanna@gmail.com

Received: May 10, 2017| Published: June 07, 2018

\section{Introduction}

Myringoplasty is a surgical procedure done for simple repair of tympanic membrane (TM) perforations involving the pars tensa of the TM. It doesn't involve reconstruction of the ossicular chain or inspection of the middle ear for disease. A graft is placed over or under the tympanic membrane so as to act as a scaffold over which epithelium can grow. The main purpose of performing a myringoplasty is to avoid recurrent disease of the middle ear cavity. Additionally, there may be some improvement in the hearing as well. Different tissue grafts are used for this purpose like temporalis muscle fascia, cartilage, cartilage- perichondrium composite, perichondrium, fat and venous graft. Apart from the use of antimicrobials to treat CSOM, a variety of techniques have evolved over the past few centuries in an attempt to close the tympanic membrane perforation and prevent recurrent infection of the middle ear. The attempt at repairing the tympanic membrane began in 1640 with Benzer's experiment with a pig bladder stretched over an ivory tube which was placed in the external canal to seal TM perforation. Thereafter in 1876, Roosa ${ }^{1}$ introduced cauterizing of the TM perforation margin to stimulate healing when he applied silver nitrate to the rim of perforation. Blake ${ }^{2}$ introduced paper patching in 1887 and in 1919, Joynt ${ }^{3}$ combined the techniques of paper patching with cauterizing of tympanic membrane perforation rim.

The modern era of myringoplasty ushered when Wullstein ${ }^{4}$ could produce results using split skin grafts. Hermann ${ }^{5}$ introduced temporalis fascia (1958), vein graft was introduced by Shea $^{6} \&$ Reinberg ${ }^{7}$ used fat (1962); Moon $^{8}$ used the loose areolar tissue overlying the temporalis facsia (1970). The advantages of connective tissue graft over skin graft became apparent. Homograft facsia were used in the 60's and 70's with variable success. Tragal and auricular cartilage and perichondrium are other commonly used graft materials.

Temporalis fascia is now-a-days the most commonly used graft and is the material of choice for reconstruction of the tympanic membrane. Refinements applicable in particular situations have diversified the types of tympanic membrane reconstructions and with evolving techniques and use of minimal intervention; it has become a day care procedure. With the introduction of endoscopes, the surgeon can access difficult areas without resorting to much tissue damage.

\section{Materials and methods}

A hospital based prospective, comparative clinical study was conducted in patients presenting with safe type of Chronic Suppurative Otitis Media either unilateral or bilateral involvement who subsequently underwent Myringoplasty. The basic criterion of inclusion was safe type of CSOM, with central perforation with no history of any complication with an ear that has been dry for atleast 6 months. The patient must have normal middle ear mucosa, as evaluated by microscopic examination. Good cochlear reserve was also determined in these patients by a pure tone audiometry (PTA). The study group included patient age between 10 years to 65 years. Tympanic membrane perforations were classified as small, medium and large or subtotal depending on the area of the membrane involved. Those with a perforation upto $25 \%$ of the tympanic membrane area were called small, between $25-50 \%$ were called medium and more than $50 \%$ were called large or subtotal depending on the appearance of the perforation. PTA was done using frequencies of $250 \mathrm{kHz}$, $500 \mathrm{kHz}, 1000 \mathrm{kHz}, 2000 \mathrm{kHz}, 4000 \mathrm{kHz} \& 8000 \mathrm{kHz}$. Air and bone conduction thresholds were determined and documented. A total of 132 patients aged between 12 years to 65 years with a dry, central perforation were included in the current study. A thorough statistical analysis of the results was done. As three tissue grafts were used in the process, the whole study population was divided into 3 groups and results were then compared:

\section{Group A-Temporalis Fascia (n-62)}

2. Group B-Ear Lobule Fat (n-38)

3. Group C-Perichondrium from Tragal cartilage (n-32)

The operation, myringoplasty was performed by a transcanal, postauricular or an endaural approach. Post-operative audiometric assessment was done after 6 weeks and then again after 3 months of surgery. Patients were advised follow up at every 3 month interval for the next one year. The patients were advised to keep their ear 
absolutely dry. Antihistaminics were continued for the next 3 weeks.

The graft uptake of the study population was $84.85 \%$. Group A $(88.71 \%)$ had the maximum graft uptake followed by group B $(81.58 \%)$. Hearing improvement less than or equal to $25 \mathrm{~dB}$ assessed by pure tone audiometry after 3 months of surgery was considered successful in the present study. Hearing between $>15-25 \mathrm{~dB}$ assessed by pure tone audiometry was observed in maximum cases with 36 , 8 and 20 cases in each of groups A,B and C. In group B however, maximum cases had post operative hearing levels between $0-15$ dB. Persistent perforation $(15.15 \%)$ was the most common late complication seen at follows up, followed by retractions $(6.82 \%)$.

\section{Discussion}

Pardia et al., ${ }^{9}$ achieved $80 \%$ success using temporalis fascia. While Mukherjee ${ }^{10}$ could obtain $92 \%$ success rate as far as graft acceptance is concerned with fat as graft material for myringoplasty. Williamson PA et al., ${ }^{11}$ advocated the use of posterior tragal perichondrium for small and medium sized perforations. Desarda ${ }^{12}$ could get $96 \%$ success rate using perichondrium.

In the present study, hearing improvement less than or equal to $25 \mathrm{~dB}$ assessed by pure tone audiometry after 3 months of surgery was considered successful. In 1971, Strahan et al., ${ }^{13}$ concluded that hearing restoration could be judged as successful if the average post operative air- bone gap was less than $10 \mathrm{~dB}$ or if air conduction was less than $30 \mathrm{~dB}$. Mendel L et al. ${ }^{14}$ recommended post operative Pure Tone Audiometry in successful cases after a gap of 12 weeks from surgery In the current study, the post operative audiogram was done at 3 months after surgery, which is in accordance to the recommendations made by Mendal et al ${ }^{14}$ In this study, post operative hearing level of $25 \mathrm{~dB}$ or less is considered successful which is similar to the recommendations made by Straham et al. ${ }^{13}$ However, the result with fat graft myringoplasty in this study is much higher than that obtained by De $\mathrm{S}$ et al. ${ }^{15}$

\section{Conclusion}

In conclusion, myringoplasty is recommended for repairing simple tympanic membrane perforations. Proper case selection with good cochlear reserve and a dry and safe ear give satisfactory results. In our study, perforation closure was much higher when temporalis fascia was used as a graft material as compared to tragal perichondrium or lobule fat graft. Hearing improvement was however comparable in all groups. Better graft uptake was seen with smaller perforations and younger age.

\section{Acknowledgments}

None.

\section{Conflict of interest}

The author declares there is no conflict of interest.

\section{References}

1. Roosa. As stated in Disease of Ear. 3rd edition, New York: Williams, Woods \& Co. 1876.

2. Blake CJ. Transactions of the First Congress of the International Otological Society (abstract). New York: D. Appleton and Co. 1887. p. 125.

3. Joynt. Repair of Drum, Iowa Medical Society.1919; 9/51.

4. Wullstein H. Theory and practice of tympanoplasty. Laryngoscope. 1956;66(8):1076-1093.

5. Heerman H. Tympanic membrane plastic with temporal fascia. Hals Nasen Ohrenh. 1960. $136 \mathrm{p}$.

6. SHEA JJ. Vein graft closure of ear drums perforations. J Laryngol Otol. $1960 ; 74: 358-62$.

7. Ringenberg JC. Fat graft tympanoplasty. Laryngoscope. 1962;72:188-192.

8. Moon CN. Loose areolar connective tissue: A graft for otologic surgery. Laryngoscope. 1973;83(5):771-7.

9. Parida PK, Nochikattil SK, Surianarayanan G, et al. A Comparative Study of Temporalis Fascia Graft and Vein Graft in Myringoplasty. Indian $J$ Otolaryngol Head Neck Surg. 2013;65(Suppl 3):S569-S574.

10. Mukherjee M, Ranjan Paul. Minimyringoplasty: Repair of Small Central Perforation of Tympanic Membrane by Fat Graft: A Prospective Study. Indian J Otolaryngol Head Neck Surg. 2013;65(4):302-304.

11. Williamson PA, Thomas DM, Beasley P. Perichondrium Harvesting For Myringoplasty. Clinical otolaryngology and allied sciences. 1999;24(4):252-254.

12. Desarda KK, Bhisegaonkar DA, Gill S. Tragal Perichondrium and Cartilage in Reconstructive Tympanoplasty. Indian Journal of Otolaryngology and Head and Neck Surgery. 2005;57(1).

13. Strahan RW, Acqurelli M, Ward PH. Tympanic membrane grafting. Analysis of materials and techniques. Ann Otol Rhinol Laryngol. 1971;80(6):854-60.

14. Mendel L, Kuylen SR. A clinical comparison of the result of two different methods of closing tympanic membrane perforation. J Laryngol Otology. 1985;99:339-342.

15. De S, Karkanevatos A, Srinivasan VR, et al. Myringoplasty using a subcutaneous soft tissue graft. Clin Otolaryngol Allied Sci. 2004;29(4):314 7. 